\title{
EMPREGABILIDADE DO MÉTODO FUZZY CLUSTERING NA CARACTERIZAÇÃO DOS CLIMAS REGIONAIS DA PORÇÃO NORDESTE DO ESTADO DE MINAS GERAIS
}

Fabrício Lisboa Vieira Machado ${ }^{1}$

\section{Resumo}

A abordagem estática do clima historicamente o avaliou como variável cartesiana, cujos limites eram passíveis de delimitação. Entretanto o clima se manifesta em estados temporais dos mais variados, sendo necessário rever seus métodos e técnicas de análise. Para tanto, objetivou-se verificar a participação da Serra do Espinhaço na organização escalar das variáveis climáticas em escala regional, na porção nordeste de Minas Gerais, através do modelo fuzzy cluster, que permite a associação de um mesmo dado a diversos conjuntos simultaneamente. Os resultados segmentaram a região em quatro agrupamentos, onde fora possível ratificar o papel conjunto do relevo e dos controles sinóticos na organização escalar regional.

Palavras-chave:fuzzy cluster; climas regionais; Serra do Espinhaço

\begin{abstract}
Staticclimate approach historicallyevaluated as Cartesianvariable, whoseboundariesweresubjecttodelimitation. However, climateismanifested in distinct temporal states, beingnecessarytoreviewtheirmethods and analysistechniques. Therefore, thisstudyaimedtoverifytheparticipation of the Espinhaço in theorganizationscale of climatevariableson a regional scale, in thenortheasternpart of Minas Gerais, throughthefuzzy cluster model, whichallowstheassociation of thesame data tomultiple sets simultaneously. The resultssegmentedregioninto four clusters, where it hadbeenpossibletoratifythe joint role of relief and thesynopticcontrols in organizing regional scale.
\end{abstract}

Key-words:fuzzy cluster; regional climate; Espinhaço Mountains

1 (Mestrando em Geografia e Análise Ambiental - PPGG/IGC/UFMG); fabriciolvm@hotmail.com 


\section{1- INTRODUÇÃO}

A concepção dinâmica do clima, enquanto sucessão habitual dos tipos de tempo sobre determinada área, viera suplantar a visão simplista das abordagens estáticas até então desenvolvidas, em que muitas vezes eram empregadas uma ou duas variáveis para caracterizar o comportamento dos elementos climáticos em escala regional ou mesmo local, além de delimitar cartesianamente seus limites e transições. Tal visão, converge no sentido a ofuscar a ideia de ritmo de manifestação dos controles atmosféricos e sua repercussão espacial diferencial sobre as superfícies terrestres, expressa em seus estados médios, habituais e, sobretudo, nos desvios rítmicos associados (eventos extremos de chuva, períodos prolongados de veranico, episódios de geada, etc.).

Modelos de classificação climática, além de metodologias de pesquisa orientadas às diferentes organizações escalares, foram produzidos na tentativa de se conhecer, seja em linhas gerais ou à luz da concepção do ritmo, os aspectos do clima das mais variadas regiões. A iniciarse por Köppen, que em 1901, produzira a primeira proposta de classificação climática quantitativa para o globo terrestre e que é reconhecida e utilizada até os dias atuais, conforme verificou Alvares et. al. (2013, p. 711), nas produções das ciências geográfica, climatológica, meteorológica, na ecologia e na agrometeorologia.

O modelo de classificação proposto, de caráter empírico ou genérico, consiste-se na observação dos elementos climáticos temperatura e precipitação, conforme a distribuição das porções vegetacionais de cada região. No contexto brasileiro, tomando a Serra do Espinhaço em Minas Gerais como exemplo, tem-se bom esboço da distribuição florística diferencial entre as bordas leste (ocupada por Mata Atlântica, em seus estados já avançados de derivação) e a borda oeste (ocupada predominantemente pelas fitofisionomias do Cerrado), conforme observado no Inventário Florestal do estado (ZEE-MG, 2009). Dessa forma, tornase pertinente pensar no papel do orógeno em questão na segmentação de pelo menos dois climas regionais distintos em Minas Gerais, diluídos em meio às classificações climáticas de caráter estático, como as baseadas no modelo de Köppen, que ora caracterizam ambas as bordas como tipo Aw (clima tropical de savana com estação seca de inverno), com pequenos enclaves do tipo Cwa (clima temperado úmido com inverno seco e verão quente), observado em Júnior (2009, p), ora uma mescla entre os já referidos tipos com As (com verão seco) e Cwb (com verão temperado), como no recém publicado Alvares et. al. (2013).

Há ainda de se considerar que a indicação de períodos secos e úmidos se dá preferencialmente e de maneira muito mais satisfatória, através do cálculo do balanço hídrico 
proposto por Thornthwaite em 1948 e aprimorado por Mather em 1955, elucidados por Tubelis\&Nascimento (1984), em que são levadas em consideração variáveis que tangem inclusive o potencial de armazenamento de água dos solos, a eficiência da evapotranspiração e uma representativa série histórica de dados de precipitação (comumente as Normais Climatológicas do Brasil 1961-1990). O resultado indica os períodos anuais em que estão concentrados os déficits e excedentes hídricos, além dos períodos de retirada e reposição da água no sistema.

De fato, tais classificações são importantes para a compreensão dos climas regionais e para o manejo organizado das reproduções humanas no espaço pelos órgãos gestores. Contudo, a não abordagem da atmosfera em seu caráter dinâmico, contemplando a evolução e repercussão das massas de ar e sistemas frontais, apesar de intrinsecamente embutidos nos resultados médios observados nos modelos de Köppen e Thornthwaite\&Mather, acaba por ignorar a ideia do ritmo de sucessão dos tipos de tempo. E ao se trabalhar com medidas de tendência central nos referidos modelos é também suprimida a noção de frequência de participação de determinada localidade em cada uma das tipologias propostas e principalmente, em mais de uma delas, o que é perfeitamente possível, tendo em vista a gama de tipos de tempo observáveis nas áreas tropicais.

Para tanto, necessário seria um modelo estatístico de agrupamento (cluster) em que um mesmo dado pudesse pertencer a diferentes classes ao mesmo tempo, o que resolveria, por exemplo, problemas de estações meteorológicas localizadas em áreas de transição entre domínios climáticos regionais e cujo dado médio é forçado a pertencer a uma única tipologia, simplesmente por exceder o limiar que a distingue das demais.

Esse mesmo modelo permitiria avaliar ainda a sazonalidade observada em um dado conjunto de variáveis climáticas, cuja resposta elencaria uma localidade em um ou outro conjunto com maior ou menor grau de pertinência, conforme a predominância de um controle atmosférico em cada estação do ano. Isso ajustaria os resultados ao modelo de classificação climática proposto por Strahler, que segundo Nóbrega (2010), é conhecido pelo caráter genético descritivo-explicativo, baseado na natureza dos movimentos e processos dos sistemas atmosféricos, fatores verdadeiramente ativos no que diz respeito à configuração do tempo e clima de uma região.

Nesta perspectiva, parece salutar a empregabilidade da Teoria dos Conjuntos Fuzzy e do método Fuzzyclustering. Introduzida por LoftZadeh na década de sessenta, a lógica nebulosa dera um passo no progresso científico e tecnológico ao romper com a limitação imposta pela tradicional lógica binária (ROCHA et. al., 2012). Nesta última, ao considerar como "secas" todas as cidades cuja umidade relativa do ar anual média fosse inferior a $40 \%$, uma cidade A com média 
em 41\% não seria assim considerada, simplesmente por não atender ao critério (na lógica binária assumiria um valor 0 , simplesmente por não possuir pelo menos $40 \%$, valor 1). Porém, com a lógica fuzzy, baseada na aceitação das incertezas, a cidade A assumiria um valor de pertinência que a elencaria, simultaneamente, tanto ao conjunto das chamadas cidades "secas", quanto a um segundo provável conjunto de cidades "moderadamente secas”, por exemplo.

Para alcançar tais produtos, o método utiliza de medidas de similaridade em seu processo de execução, calculadas com base na distância entre dois vetores (como por exemplo, a distância euclidiana). Um algoritmo é empregado no sentido de permitir a associação de um ou mais desses vetores (objetos) a dois ou mais clusters, o que evita a associação forçada a um único destes, por objetos localizados nas bordas entre distintos agrupamentos. De maneira geral, são concedidos coeficientes de filiação que indicam, entre zero e um, parciais pertencimentos.

Sendo assim, de posse de tal método seria possível, por exemplo, avaliar a influência da Serra do Espinhaço em sua porção setentrional na configuração dos elementos climáticos das bordas leste e oeste e sua respectiva organização escalar? E qual seria a frequência de pertencimento de uma região à determinada tipologia climática? Sem dúvida, tais questões se revelam pertinentes à pesquisa científica em climatologia, haja a vista a carência bibliográfica de estudos que contemplem as regiões norte e nordeste de Minas Gerais. O conhecimento das escalas superiores do clima ainda é importante no sentido da integração escalar, visto que as atividades humanas em superfície exercerão influência na configuração dos elementos climáticos de maneira diferencial em cada tipo de tempo, cuja gênese só poderá ser encontrada nas escalas de nível no mínimo regionais. Dessa forma, o conhecimento do clima enquanto elemento dinâmico subsidiará uma melhor tomada de decisão, sobretudo no que tange ao ordenamento espacial, capaz de integrar os municípios às manifestações do clima em seus estados mais variados.

\subsection{Objetivos}

Diante do quadro exposto, objetiva-se de maneira geral, verificar a participação da Serra do Espinhaço na organização escalar das variáveis climáticas em escala regional, sobretudo na porção norte e nordeste de Minas Gerais, verificando a empregabilidade do método fuzzyclustering na identificação de tais unidades climáticas.

Para tanto, tem-se como objetivos específicos i) a identificação de padrões e ritmos climáticos associados aos períodos secos e úmidos da série histórica trabalhada; ii) analisar o nível 
de pertencimento de cada estação aos diferentes agrupamentos nebulosos modelados; iii) comparar os resultados obtidos junto à classificação climática de Köppen, verificando a frequência de manifestação das estações em diferentes tipologias; e iv) produção de documentos cartográficos analíticos e de síntese, como por exemplo, o mapa de distribuição das unidades climáticas modeladas.

\section{2- MATERIAIS E MÉTODOS}

Os passos iniciais necessários à realização da pesquisa consistiram na produção do banco de dados climatológico e na revisão bibliográfica das temáticas de interesse. Para tanto, adquiriuse junto ao Instituto Nacional de Meteorologia (INMET), a série histórica dos dados coletados pelas estações convencionais na área de estudo, entre os anos de 1961 a 2012. A grande maioria deles apresentara falhas na cobertura do registro, em que por vezes foram registradas descontinuidades diárias ou mesmo anuais, o que não representou impactante ônus diante dos propósitos do trabalho, voltados a uma clusterização regional e sazonal. Porém, a significativa inconsistência presente nos dados de precipitação entre as estações selecionadas, não pudera ser corrigida ou minimizada e de tal forma, optou-se por trabalhar com os valores normalizados das Normais Climatológicas do Brasil 1961-1990 (RAMOS et. al., 2009), de modo a torna-los comparáveis quando da execução do modelo.

Ademais foram selecionados os dados históricos diários de temperatura média compensada e umidade relativa do ar dos municípios mineiros de Teófilo Otoni, Araçuaí, Caratinga, Itamarandiba, Diamantina, Montes Claros, Pedra Azul e Salinas, além do município baiano de Caravelas, haja vista a distribuição dos mesmos pelas porções leste e oeste da Serra do Espinhaço, em diferentes cotas altimétricas e em distintos tipos de uso e cobertura da terra, conforme figura 1. As leituras desenvolvidas, por sua vez, foram baseadas nos estudos voltados aos modelos de classificação climática empíricos e genéticos, ao papel do relevo na configuração dos elementos climáticos em escala local e regional e, sobretudo, na aplicação do modelo estatístico fuzzyclustering.

O tratamento inicial dos dados fora realizado em parte pelo Laboratório de Estudos Territoriais do Instituto de Geociências da Universidade Federal de Minas Gerais (LESTE), responsável pela conversão do formato padrão do INMET e sua compilação em plataforma IBM SPSS Statistics. Neste mesmo software foram calculadas pelo autor as médias históricas mensais e 
demais estatísticas descritivas para os períodos secos e úmidos ${ }^{1}$ de cada município, além de organizados os dados para a plotagem no software SPLUS 2000, responsável por rodar o modelo fuzzyclustering e construir os agrupamentos de dados, por meio da caixa de ferramenta Fuzzypartitioning.

Figura 1. Mapa hipsométrico com a distribuição das estações meteorológicas mineiras trabalhadas.
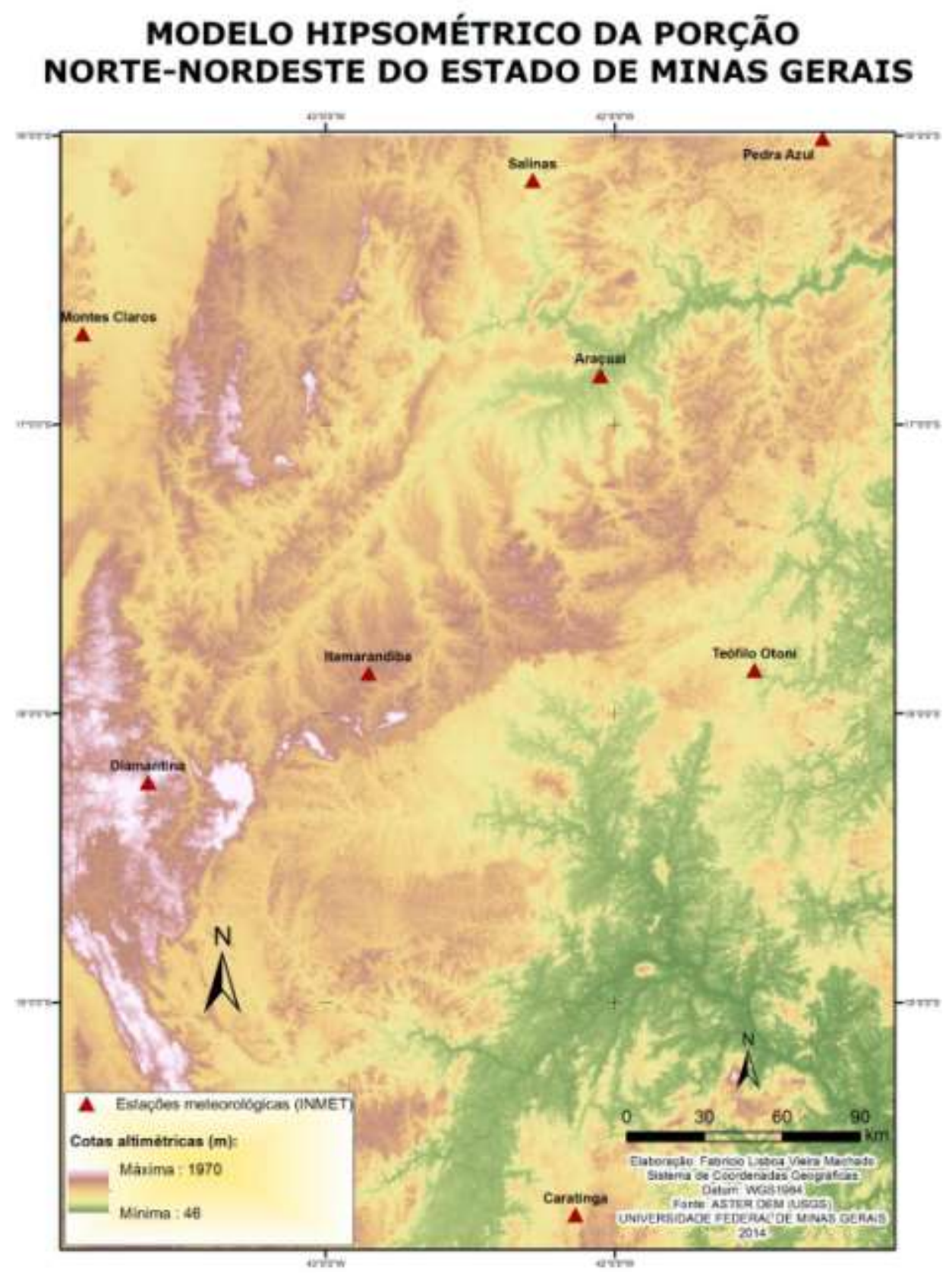

\footnotetext{
${ }^{1}$ A estimativa dos períodos secos e úmidos foi baseada nos cálculos do balanço hídrico realizados pelo INMET, através dos dados das Normais Climatológicas do Brasil (1961-1990), em que verificou-se majoritariamente o mês de setembro como o de maior déficit hídrico na quase totalidade das estações, assim como dezembro como mês de maior excedente de água no sistema.
}

Cadernos do Leste 
O método fuzzyclustering baseia-se na minimização da função objetivo, que por sua vez, representa a distância entre os dados e os centros dos grupos. Através do algoritmo fuzzy cmeans, desenvolvido por Bezdek em 1981, conforme aponta Ferreira (2012), fora possível a associação de cada dado a mais de um grupo com um grau de pertinência (membership) específico. Para alcançar tal objetivo, o algoritmo realiza inúmeras iterações na busca de uma "configuração ótima” de parâmetros para minimizar a função e somente cessa ao encontrar erro de quantização invariável, mesmo que mais iterações sejam realizadas. Com o processo de minimização, os dados são associados aos grupos de forma que, quanto menores forem as distâncias entre o dado X e o vetor protótipo C associado a ele, menor será o valor da equação, expressa conforme Equação 1 e onde, d(Ci; xj), é a distância entre o vetor de dados xj e o protótipo do grupo Ci, c é o número de grupos a ser determinado pelo algoritmo, n é o número de dados no conjunto de dados e Uh é uma matriz binária chamada "matriz de partição", de dimensões c x n.

$$
J_{C M}\left(U_{h}, \mathcal{C}\right)=\sum_{i=1}^{c} \sum_{j=1}^{n} u_{i j} d\left(\vec{C}_{i}, \vec{x}_{j}\right)^{2}
$$

Optou-se pela criação de quatro clusters, de modo que fossem no mínimo representativos, a priori, das faixas úmidas de leste da Serra do Espinhaço, recobertas por resquícios de Mata Atlântica; das porções elevadas do orógeno, com seus afloramentos quartzíticos e mosaicos de Unidades de Conservação que resguardam paisagens naturais; das faixas ocidentais recobertas pelas fitofisionomias de Cerrado; e, possivelmente, das terras baixas costeiras sob maior influência oceânica. Os dados de entrada do modelo foram ainda normalizados durante a sua execução, tendo em vista o grande espectro de variabilidade entre as escalas dos atributos mensurados (precipitação, temperatura e umidade relativa do ar). Os valores de entrada podem ser verificados conforme tabela 1 abaixo. 
Tabela 1. Variáveis embutidas no modelo Fužypartitioning. A normalização dos mesmos fora realizada dentro do próprio pacote estatístico.

\begin{tabular}{cccccc} 
ID & Estação & Período & $\begin{array}{c}\text { Precipitação } \\
\text { acumulada }(\mathbf{m m})\end{array}$ & $\begin{array}{c}\text { Temperatura média } \\
\text { compensada }\left({ }^{\circ} \mathbf{C}\right)\end{array}$ & $\begin{array}{c}\text { Umidade relativa } \\
\text { do ar }(\mathbf{\%})\end{array}$ \\
\hline 1 & Araçuá & Úmido & 152,30 & 25,694 & 72,726 \\
1 & Araçuaí & Seco & 8,93 & 23,204 & 62,911 \\
2 & Caratinga & Úmido & 191,30 & 22,967 & 77,727 \\
2 & Caratinga & Seco & 23,17 & 19,133 & 73,094 \\
3 & Caravelas & Úmido & 145,83 & 25,433 & 81,467 \\
3 & Caravelas & Seco & 76,37 & 22,300 & 81,433 \\
4 & Diamantina & Úmido & 230,20 & 19,903 & 80,113 \\
4 & Diamantina & Seco & 18,60 & 16,906 & 69,215 \\
5 & Itamarandiba & Úmido & 202,90 & 21,518 & 81,005 \\
5 & Itamarandiba & Seco & 15,90 & 17,818 & 74,159 \\
6 & Montes Claros & Úmido & 215,70 & 23,267 & 67,861 \\
6 & Montes Claros & Seco & 8,83 & 21,167 & 58,818 \\
7 & Pedra Azul & Úmido & 153,37 & 23,775 & 73,957 \\
7 & Pedra Azul & Seco & 15,37 & 20,453 & 70,868 \\
8 & Salinas & Úmido & 143,90 & 24,696 & 75,766 \\
8 & Salinas & Seco & 18,43 & 22,045 & 60,599 \\
9 & Teófilo Otoni & Úmido & 160,50 & 24,567 & 74,439 \\
9 & Teófilo Otoni & Seco & 24,70 & 20,667 & 73,481 \\
\hline
\end{tabular}

Com os agrupamentos nebulosos construídos e de posse dos valores de pertinência para cada estação entre tais grupos, foram analisados os fatores geográficoclimatológicos envolvidos na distribuição dos dados. Como auxílio, fora realizada através do software ArcGIS 10.1, a interpolação dos coeficientes de associação de cada estação distribuída entre os clusters, além do hard cluster específico de cada estação (lógica clássica), na tentativa de se alcançar a síntese climática regional (esboço de prováveis unidades climáticas). Selecionou-se o método do inverso da distância ponderada (IDW), em virtude da relativamente baixa malha amostral de estações, obtendo nuances da distribuição espacial mais expressivos (como o aparecimento dos círculos concêntricos ou bullseye, que neste caso foram salutares).

Calculou-se ainda, através do software Microsoft Excel 2013, a frequência de pertencimento de uma estação às tipologias de Köppen informadas pela bibliografia, verificando, sobretudo, a participação dos sistemas atmosféricos na sazonalidade de tal distribuição. Para tanto, lançou-se mão de imagens de satélite e cartas sinóticas, obtidas junto ao Instituto Nacional de Pesquisas Espaciais (CPTEC/INPE) e à Marinha do Brasil, no intuito de auxiliar na identificação dos controles atmosféricos predominantemente atuantes nas porções norte e 
nordeste de Minas Gerais. Trabalhos como os produzidos por Nimer (1966) e Cavalcanti et. al. (2009) foram de substancial relevância para compreender a distribuição dos clusters a partir da perspectiva dinâmica do clima, acompanhada da interação com os controles de superfície, o que permitiu avaliar a eficácia dos fuzzy clusters para a pesquisa científica climatológica.

\section{3- RESULTADOS E DISCUSSÃO}

A análise dos agrupamentos nebulosos modelados revelou, inicialmente, razoável quantidade de estações cujo período úmido estivera mais predominantemente associado a um mesmo cluster (I). Os municípios de Araçuaí, Caravelas, Montes Claros, Pedra Azul, Salinas e Teófilo Otoni apresentam características geomorfológicas e fitogeográficas semelhantes, no que diz respeito à porção do espaço em que estão assentados. As altitudes das referidas extensões municipais em território mineiro variam de pouco mais de 350 metros, a cotas médias próximas de 600 metros, o que não é significativamente representativo quando pensado o gradiente barométrico existente na variação da temperatura a cada 100 metros: cerca de $0,6^{\circ} \mathrm{C}$, aproximadamente.

Os relevos mamelonares descritos por Ab’Saber (2003), com seus batólitos ou inselbergs aflorados, em formações do tipo "pão-de-açúcar", revelam ainda certa homogeneidade na paisagem entre os municípios descritos. A própria faixa latitudinal em que estão localizados (entre os paralelos $16^{\circ}$ e $17^{\circ} \mathrm{S}$ ) é fator a ser elencado na gênese do provável clima regional a que estão submetidos, haja vista a similaridade na incidência de radiação solar, duração dos dias, etc. A cobertura da terra, marcadamente caracterizada pela transição dos biomas da Mata Atlântica e do Cerrado, em seus estados avançados de supressão, ainda contribui para ratificar a inserção das estações em um mesmo cluster (I) com maiores graus de pertencimento, se comparado às demais.

Vale lembrar, que o referido agrupamento reuniu estações cujos dados associavam-se somente ao período úmido da série histórica trabalhada, o que permite aferir que o cluster (I) é fortemente caracterizado por situações temporais habituais das estações chuvosas de sudeste nesta latitude e pelo fator relevo. Isso porque os centros de baixa pressão formados sobre o continente, a participação dos sistemas frontais e das zonas de convergência de umidade, estão associados à instabilidade atmosférica típica de verão, à elevada convectividade e, portanto, à imposição do ar resfriado nas camadas elevadas da troposfera sobre a superfície. Quanto maior a temperatura, maior o grau de agitação das moléculas, o que, por outro lado, resulta no aumento da densidade das mesmas quanto menor for a temperatura. 
De tal maneira, a imposição dos sistemas instáveis, cuja gênese se dá predominantemente em escalas zonais e regionais, acaba por desorganizar ou mesmo suprimir os climas produzidos nas escalas inferiores em tais condições temporais, como os climas urbanos, a exemplo. Resultado disso é a manifestação em maior força dos controles naturais, conforme observou Machado (2014) através da análise rítmica do clima realizada no Aglomerado da Serra, em Belo Horizonte, e como é o caso do relevo na gênese do cluster (I).

Contudo, ao observar os coeficientes de associação de cada estação aos variados clusters (tabela 2), é notória a pouca representatividade do município de Caravelas (BA) e, intrinsecamente, de seu contexto espacial, na conformação do primeiro agrupamento $(42,6 \%)$. Isso muito provavelmente está associado ao balanço hídrico diferencial da estação, cujos períodos de maiores déficits e excedentes são relativamente distintos dos predominantemente encontrados nas estações mineiras (março e novembro, no caso baiano, respectivamente).

O motivo disso está ligado à participação direta do Oceano Atlântico na manutenção do campo hígrico local e aos mecanismos de circulação secundária atuantes nas zonas costeiras do Nordeste brasileiro, como por exemplo, os distúrbios ondulatórios de leste que contribuem para a pluviosidade média concentrada mais habitualmente nas estações de outono e primavera. 
Tabela 2. Coeficientes de associação das variáveis climatológicas aos diferentes fužyy clusters. Valores de maior representatividade grafados em negrito.

\begin{tabular}{cccccc}
\hline ID & Estação & Cluster I & Cluster II & $\begin{array}{c}\text { Cluster } \\
\text { III }\end{array}$ & $\begin{array}{l}\text { Cluster } \\
\text { IV }\end{array}$ \\
\hline 1 & Araçuaí & $\mathbf{0 , 6 2 6 6 4}$ & 0,10280 & 0,17114 & 0,09943 \\
2 & Araçuaí & 0,11415 & $\mathbf{0 , 6 6 0 5 9}$ & 0,09183 & 0,13343 \\
3 & Caratinga & 0,31502 & 0,07207 & $\mathbf{0 , 5 1 2 7 6}$ & 0,10016 \\
4 & Caratinga & 0,05768 & 0,06786 & 0,07124 & $\mathbf{0 , 8 0 3 2 2}$ \\
5 & Caravelas & $\mathbf{0 , 4 2 6 2 3}$ & 0,11019 & 0,32596 & 0,13763 \\
6 & Caravelas & 0,26630 & 0,11949 & $\mathbf{0 , 3 9 4 0 2}$ & 0,22020 \\
7 & Diamantina & 0,17117 & 0,09179 & $\mathbf{0 , 5 8 7 8 0}$ & 0,14924 \\
8 & Diamantina & 0,12870 & 0,19172 & 0,15505 & $\mathbf{0 , 5 2 4 5 3}$ \\
9 & Itamarandiba & 0,12609 & 0,05079 & $\mathbf{0 , 7 4 2 7 8}$ & 0,08033 \\
10 & Itamarandiba & 0,09637 & 0,11217 & 0,12516 & $\mathbf{0 , 6 6 6 3 1}$ \\
11 & Montes Claros & $\mathbf{0 , 3 6 8 8 8}$ & 0,19071 & 0,26711 & 0,17330 \\
12 & Montes Claros & 0,07184 & $\mathbf{0 , 7 5 7 6 4}$ & 0,06533 & 0,10520 \\
13 & Pedra Azul & $\mathbf{0 , 6 9 0 6 6}$ & 0,06528 & 0,16657 & 0,07749 \\
14 & Pedra Azul & 0,11296 & 0,15887 & 0,11952 & $\mathbf{0 , 6 0 8 6 4}$ \\
15 & Salinas & $\mathbf{0 , 7 7 1 4 3}$ & 0,04835 & 0,12372 & 0,05650 \\
16 & Salinas & 0,03822 & $\mathbf{0 , 8 7 7 2 5}$ & 0,03311 & 0,05143 \\
17 & Teófilo Otoni & $\mathbf{0 , 8 2 2 2 7}$ & 0,03905 & 0,09502 & 0,04367 \\
18 & Teófilo Otoni & 0,12545 & 0,12808 & 0,14072 & $\mathbf{0 , 6 0 5 7 6}$ \\
\hline
\end{tabular}

A participação de Montes Claros na composição característica do primeiro cluster também é pouco expressiva (da ordem de 36,8\%), uma vez que mesmo em período úmido, seus valores médios históricos de umidade relativa do ar são os mais baixos dentre as estações amostrais, registrando $67,86 \%$. Tal quantitativo a aproxima muito do conjunto de parâmetros responsáveis pela organização do cluster (II), a quem registra coeficiente de associação expressivo de 0,757 (ou 75,7\%) no período seco.

Juntamente da referida cidade, encontram-se mais predominantemente associados os municípios de Araçuaí e Salinas, ambos cujos dados iterados no modelo fuzzydizem respeito ao período seco. No caso de Montes Claros, fica evidente que o observado se deve à participação da Serra do Espinhaço como barreira à entrada de umidade oceânica para as porções a oeste, mas não somente. A abordagem climatológica dinâmica e a preocupação escalar intrínseca à tal ciência revela também (e talvez principalmente) a atuação do Anticiclone Subtropical do Atlântico Sul 
(ASAS), como importante fator responsável pela organização das variáveis climáticas sob as faixas territoriais das três cidades.

Ao observar as imagens de satélite adquiridas junto ao Instituto Nacional de Pesquisas Espaciais (INPE), para o período de inverno do ano de 2014 (figura 2), por exemplo, é notável a imposição desse sistema de alta pressão sobre grande parte do país. O mesmo é caracterizado como zona de descida vertical de ar, cuja atuação promove o enfraquecimento das correntes convectivas de superfície, inibe a formação de nebulosidade de grande desenvolvimento vertical e garante condições temporais estáveis. Dessa forma, a radiação solar pode incidir sobre a superfície terrestre de maneira direta em maior número de situações, o que promove o aquecimento diferencial dos diferentes tipos de cobertura. O saldo energético, portanto, resulta em elevadas amplitudes térmicas diárias, além de permitir maior manifestação dos climas produzidos nas escalas inferiores.

Contudo, mesmo com a imposição do centro de alta pressão é possível visualizar nebulosidade na faixa central do estado de Minas Gerais, prolongando-se pelo território baiano e litoral de Nordeste. Trata-se da imposição nítida do domínio macroestrutural do Espinhaço, responsável pela ascensão mecânica do ar advectado e, por vezes, sua condensação. As áreas úmidas e ainda recobertas em parte por Mata Atlântica também respondem pela nebulosidade observada no Nordeste.

Figura 2. Imagem do satélite GOES-13, na banda do infravermelho 4, às $12 \mathrm{~h}$ do dia 05 de julho de 2014, com a representação aparente da atuação do ASAS. Adaptado de Instituto Nacional de Pesquisas Espaciais. 


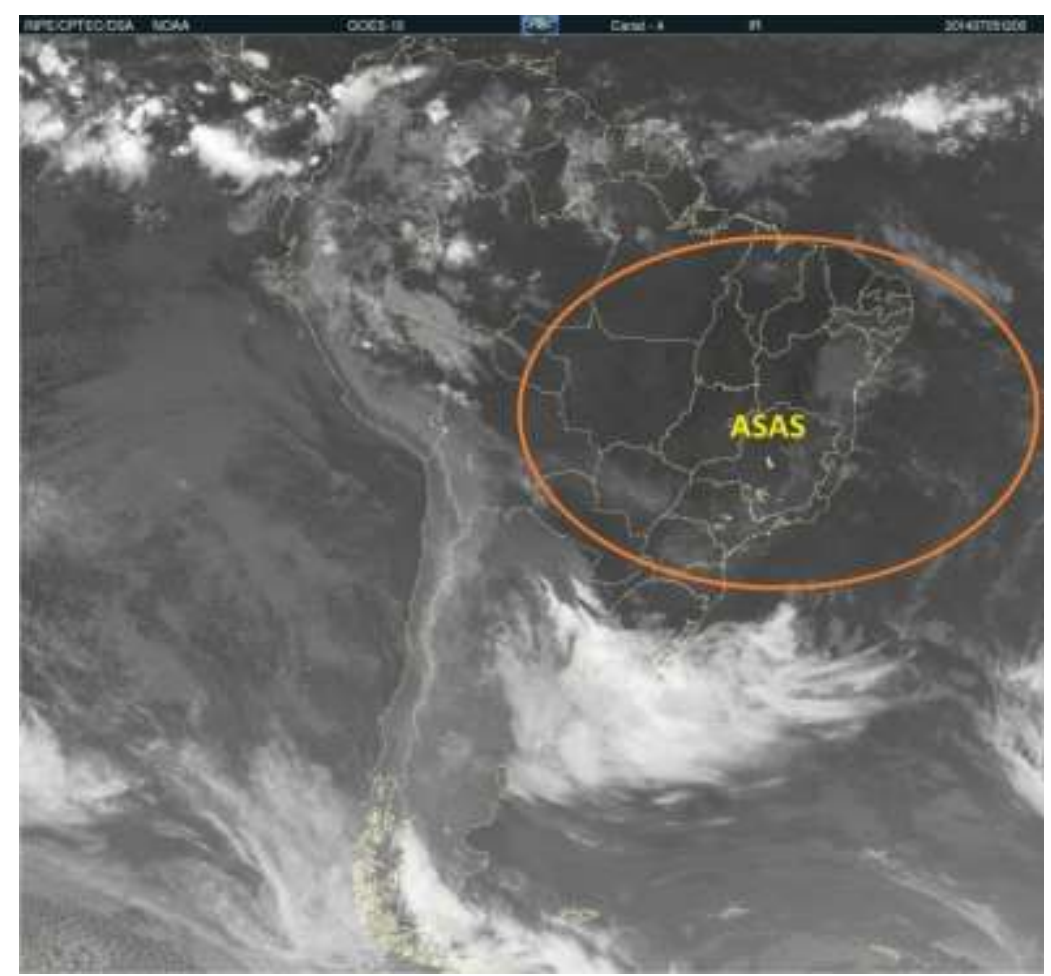

É interessante destacar também, que como célula anticiclonal, seu movimento giratório se dá no sentido anti-horário, o que resulta no registro por parte das estações meteorológicas, de vetores de direção predominante dos ventos de origem leste e nordeste, o que revela mais uma vez a ação do Espinhaço em não permitir a passagem da umidade para as bordas a oeste, onde está localizada a cidade de Montes Claros, por exemplo.

Porém, Salinas e Araçuaí encontram-se na borda leste, mas contraditoriamente a priori, também pertencem ao cluster (II). Se analisado o mapa hipsométrico, rapidamente se percebe a situação de fundo de vale em que estão instaladas as cidades. Em tipos de tempo predominantemente estáveis, conforme dito, os fatores envolvidos na organização dos climas em escalas inferiores são potencializados. Resultado disso, neste caso, é a criação dos padrões de circulação de brisa montanha-vale, capazes de confinar o ar quente no fundo de vale em variadas situações, conforme observado, por exemplo, por Machado et. al. (2013) no canyondo rio Mascates, Serra do Cipó (MG), durante o período diurno e sob tipo de tempo estável.

O cluster (III), por sua vez é caracterizado substancialmente pelas estações em patamares altimétricos mais elevados e em tipos de tempo instável. Neste grupo, através da interpretação do hard cluster, elenca-se os municípios de Caratinga, Diamantina e Itamarandiba, em série dados do período úmido, além do município baiano de Caravelas em período seco. A inclusão deste último aqui, se deve mais uma vez aos controles atmosféricos atuantes de realidade regional distinta a dos territórios mineiros e às trocas energéticas oceano-continente a que está submetido, 
responsáveis pelas configurações sazonais diferentes e que aproximam seu período aqui dito seco, à realidade regional do cluster (III).

A associação predominante de Caratinga ao cluster (III), cuja cota altimétrica não é tão elevada quanto Diamantina e Itamarandiba (que ultrapassam os mil metros de altitude), remonta também à questão latitudinal, registrada entre $19^{\circ}$ e $20^{\circ} \mathrm{S}$. Este fato, contribui para a maior frequência de participação dos sistemas frontais, orientando os tipos de tempo a condições instáveis. A proximidade com o Parque Estadual do Rio Doce e à RPPN Mata do Sossego, Unidades de Conservação que asseguram grandes extensões territoriais de Mata Atlântica preservada, também é fator justificativo para a maior inclusão da cidade ao referido cluster (input de umidade no campo higrométrico local). Porém, vale destacar que o seu coeficiente de associação é de apenas 0,512, confundindo-se muito com o cluster (I), onde registrou 31,5\% de associação. O motivo provavelmente está associado à questão altitudinal.

O quarto cluster, por fim, reúne estações que na totalidade dos casos de maior pertencimento, estão associadas aos períodos secos. Todas elas (Caratinga, Diamantina, Itamarandiba, Pedra Azul e Teófilo Otoni) ou compartilham do patamar altimétrico semelhante, ou da relativa proximidade com o oceano. Mesmo Pedra Azul, localizada em baixa latitude e em altitude de pouco mais de 600 metros, apresenta razoável coeficiente de associação (da ordem de 0,608), uma vez que se forem calculadas as distâncias mínimas das estações até o oceano, a referida cidade é aquela que se encontra mais próxima do mar em território mineiro. A superfície ainda recoberta por vegetação em grande parte (mesmo que por eucaliptais), principalmente nas porções a leste, também contribui para a manutenção de tais condições em período seco.

Ao comparar os resultados obtidos após a clusterização,com a classificação climática de Köppen, nota-se que a Serra do Espinhaço é de fato participativa na gênese de diferentes climas regionais da porção em estudo. A figura 3 e figura 4 revelam ora a participação de cada estação meteorológica na composição dos fuzzy clusters, ora nos hards clusters a que se associaram. Em ambos os períodos, vê-se claramente a protuberância dos agrupamentos clássicos em um alinhamento sentido sul - norte, associado imediatamente com o orógeno do Espinhaço.

No modelo de Köppen, porém, apesar de confeccionado em razoável dimensão escalar, não seria possível estabelecer vínculos imediatos com os aspectos sinóticos, responsáveis primários pela gênese dos climas regionais. Prova disso é a presença constante do cluster (IV) a sul, associado aos períodos secos das cidades de patamar altimétrico elevado, mas cuja umidade relativa média ainda é razoavelmente elevada (média em torno de 73\%), resposta relacionada à maior frequência de atuação de frentes do que no cluster I, por exemplo. 
Figura 3. Agrupamentos nebulosos modelados em período úmido.
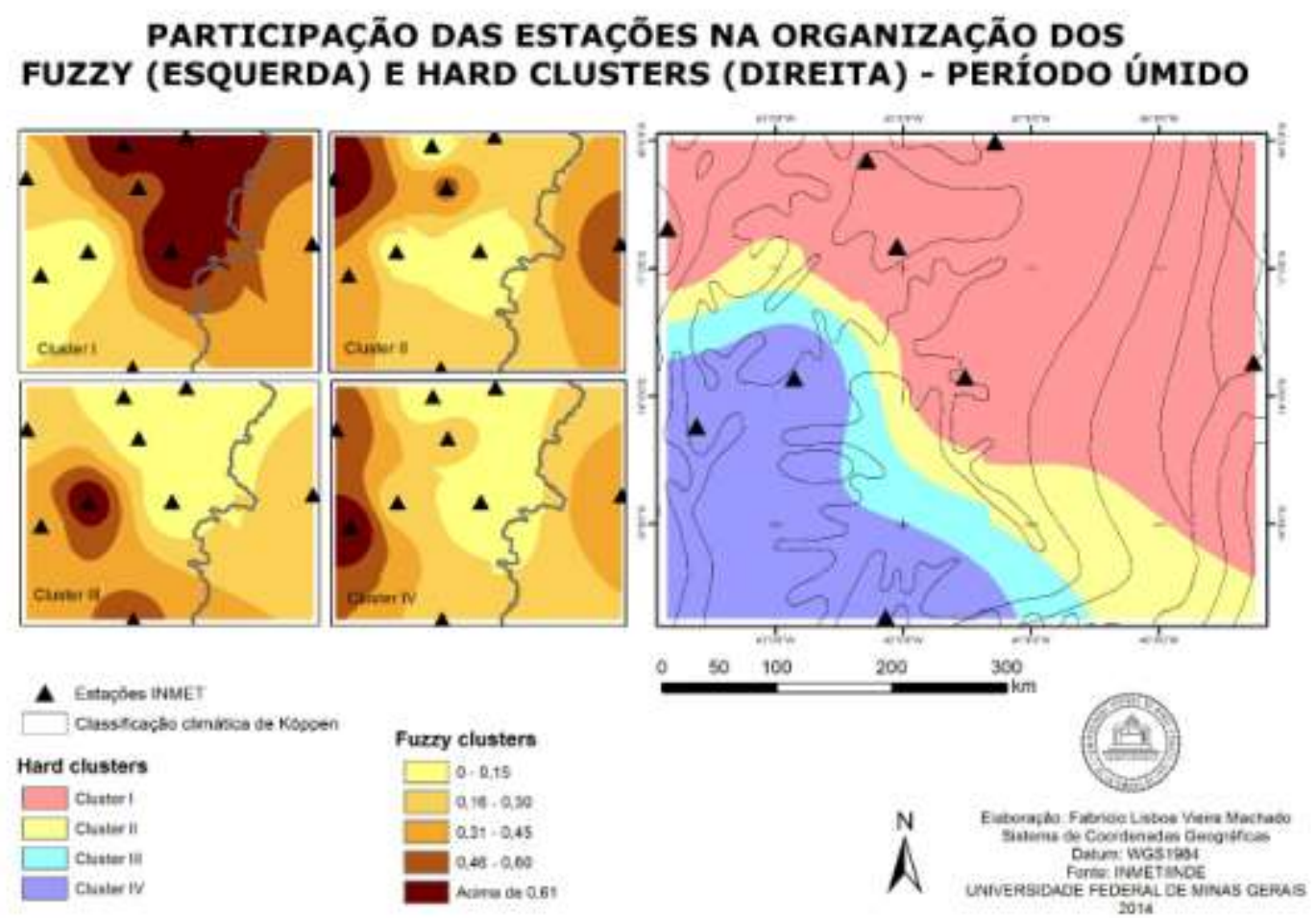

Figura 4. Agrupamentos nebulosos modelados em período seco.
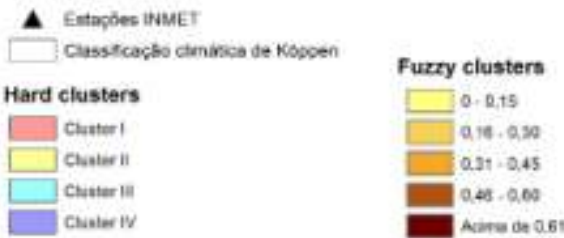

PARTICIPAÇÃO DAS ESTAÇÕES NA ORGANIZAÇĀO DOS FUZZY (ESQUERDA) E HARD CLUSTERS (DIREITA) - PERÍODO SECO
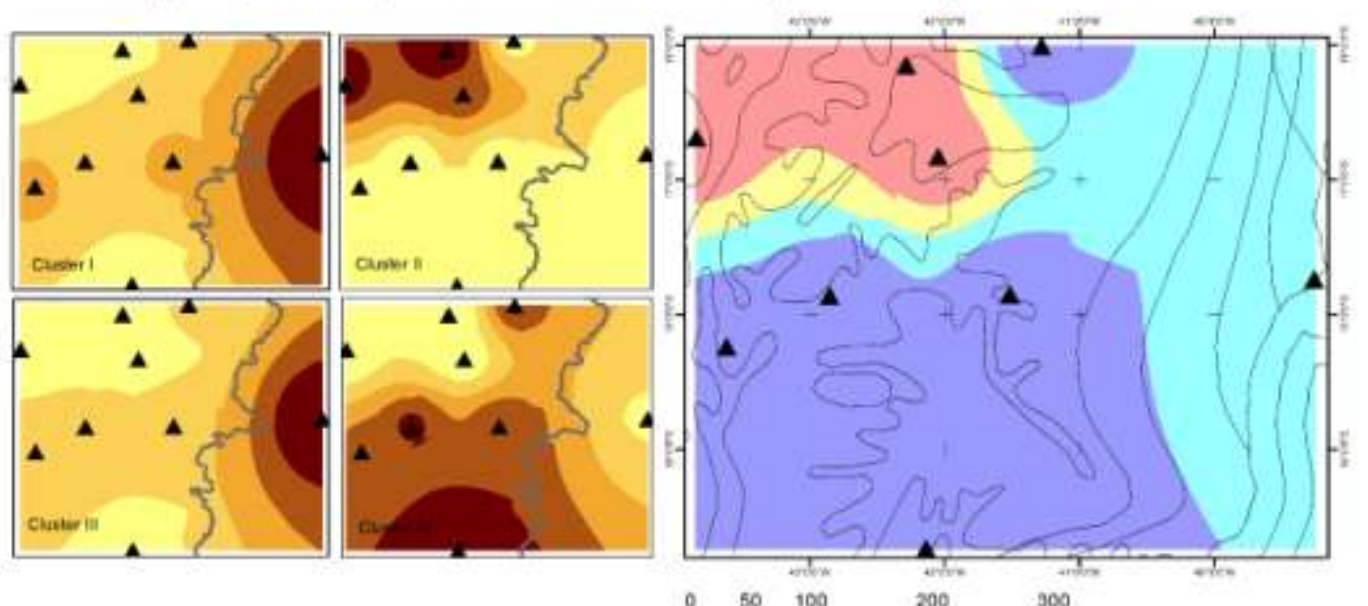

$\boldsymbol{\Delta}$ Eatapoen bivet

] Ciasticactlo elimatca de Keppen

Hard clusters
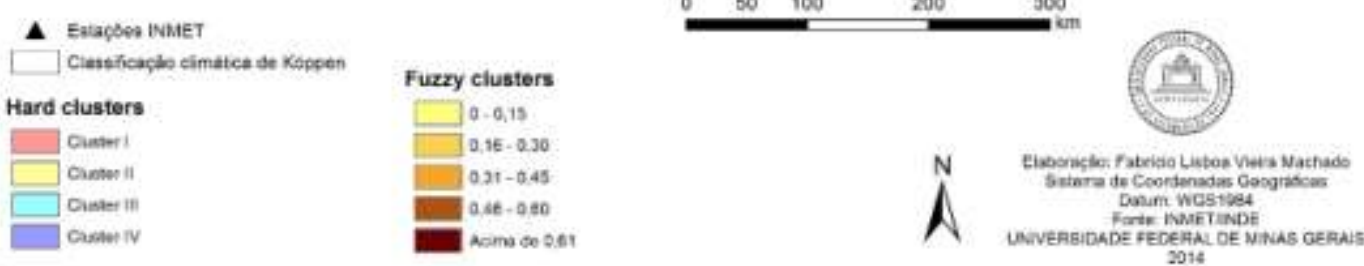

Cadernos do Leste 
Em relação à frequência, observa-se pela análise dos fuzzy clusters que as estações modeladas estiveram presentes em quatro tipologias de Köppen distintas, em território mineiro. A de maior recorrência de pertencimento com coeficiente de associação superior a $46 \%$ fora a associada aos climas Tropicais do Brasil Central, com médias de temperatura superiores aos $18^{\circ} \mathrm{C}$ em todos os meses e com seis destes de período seco, o que sugere a atuação predominante do ASAS sazonalmente. Isto reforça ainda a limitação da lógica clássica embutida no modelo, responsável por suprimir as participações dos variados tipos de tempo na configuração e reconfiguração das classificações climáticas de um território, somente aferidas com o auxílio da lógica nebulosa, somada às imagens de satélite. $O$ quantitativo das frequências pode ser visualizado na tabela 3 a seguir.

Tabela 3. Frequência de associação das estações às tipologias de Köppen, segundo os resultados dos fur:y clusters.

Tropical Brasil Tropical Brasil Tropical Brasil Central, quente - Central, quente - Tropical Brasil Central, Central,

Estação média $>18^{\circ} \mathrm{C} \mathrm{em} \mathrm{média}>18^{\circ} \mathrm{C} \mathrm{em}$ subquente - média entre mesotérmico brando todos os meses todos os meses $\left(415\right.$ e $18^{\circ} \mathrm{C}$ em pelo menos - média entre $10 \mathrm{e}$ (6 meses secos) a 5 meses secos) 1 mês $(4$ a 5 meses secos $) 15^{\circ} \mathrm{C}$

\begin{tabular}{ccccc} 
& & & & (4 a 5 meses úmidos) \\
\hline Araçuaí & 3 & 0 & 0 & 0 \\
Caratinga & 0 & 0 & 0 & 2 \\
Caravelas & 0 & 0 & 0 & 0 \\
Diamantina & 0 & 0 & 1 & 1 \\
Itamarandiba & 0 & 0 & 2 & 0 \\
Montes Claros & 3 & 0 & 0 & 0 \\
Pedra Azul & 0 & 2 & 0 & 0 \\
Salinas & 2 & 0 & 0 & 0 \\
Teófilo Otoni & 0 & 0 & 2 & 0 \\
Total & 8 & 2 & 5 & 3 \\
Frequência & $44,4 \%$ & $11,1 \%$ & $27,78 \%$ & $16,67 \%$ \\
\hline
\end{tabular}

\section{4- CONSIDERAÇÕES FINAIS}

O presente estudo preocupou-se com a avaliação da empregabilidade do modelo fuzzyclusteringna pesquisa científica climatológica, sobretudo no que diz respeito à classificação em escala regional, comumente desenvolvida através de modelos que seguem a lógica clássica e a abordagem estática do clima, suprimindo a noção de ritmo de atuação dos controles atmosféricos e os tipos de tempo associados.

Os resultados alcançados segmentaram quatro agrupamentos nebulosos característicos, associados às: i) altitudes menos elevadas das porções do norte de Minas Gerais, onde a 
participação dos sistemas instáveis reforça os aspectos naturais da paisagem em período úmido; ii) cidades encaixadas em condições de vale, cuja participação do Anticiclone Subtropical do Atlântico Sul nos períodos secos se mostra predominante; iii) cidades em elevadas cotas altimétricas sob condições instáveis e/ou em proximidade com o oceano nos períodos úmidos; iv) condições geomorfológicas semelhantes ao cluster (III), mas manifestadas em tipos de tempo estável.

Verificou-se que a Serra do Espinhaço de fato se mostra marcante na organização dos climas em escala regional, desde que observada à luz da concepção dinâmica, proposta que o presente estudo buscou contemplar através da lógica nebulosa.

Salienta-se que o trabalho visara apenas a uma primeira contribuição à utilização do método para fins de classificação climática, sendo necessária a revisão metodológica e novas submissões a testes para alcançar conclusões mais sólidas. Contudo, espera-se que o mesmo tenha contribuído para o repensar da ótica clássica, que enxerga o clima como variável cartesiana e restrita a uma ou outra variável. Se o objetivo de uma classificação seja servir de alguma forma à gestão territorial, convém então que seja feita de modo a avaliar não somente o que é habitual, mas sobretudo o que é estado especial e constantemente mutável.

\section{REFERÊNCIAS BIBLIOGRÁFICAS}

AB'SÁBER, A. Os domínios de natureza no Brasil: potencialidades paisagísticas. 4ed. Editora: Ateliê Editorial, 2007.

ALVARES, C. A.; STAPE, J. L.; SENTELHAS, P. C.; GONÇALVES, J. L.; SPAROVEK, G. Köppen'sclimateclassificationmap for Brazil. MeteorologischeZeitschrift, v. 22, v. 6, p. $711-$ 728. Alemanha, 2013.

CAVALCANTI, I. F. A.; FERREIRA, N. J. F.; JUSTI DA SILVA, M. G. A.; DIAS, M. A. F. S. (organizadores). Tempo e clima no Brasil. São Paulo: Oficina de Textos, 2009.

FERREIRA, C. Aplicação da lógica nebulosa (fuzzy cluster) na definição de unidades climáticas: estudo de caso na bacia do rio Paraíbuna - MG/RJ. Revista Brasileira de Climatologia. Ano 8, v.10, 2012

JÚNIOR, A. S. Aplicação da classificação climática de Köppen para o zoneamento climático do estado de Minas Gerais. Dissertação (Mestrado em Engenharia de Água e Solo), Programa de Pós-Graduação em Engenharia Agrícola, Universidade Federal de Lavras. Lavras, 2009.

MACHADO, F. L. V.; JARDIM, C. H. Indicadores climáticos de degradação ambiental em áreas urbanas: o Aglomerado da Serra em Belo Horizonte/Brasil. In: Experimentos em Climatologia Geográfica. Org.: Fialho, et. al. Editora: UFGD, 2014. 
MACHADO, F. L. V.; NERY, F. H.; COELHO, J. P. R., JARDIM, C. H. Aspectos do clima e paisagem em trecho do Parque Nacional da Serra do Cipó - MG: variações horárias de temperatura e umidade relativa do ar no período de 11 a 13/04/2014

NIMER, E. Circulação atmosférica do Brasil. Revista Brasileira de Geografia. n.3, ano XXVIII, pg. $232-250.1966$.

NÓBREGA, R. S. Um pensamento crítico sobre classificações climáticas: de Köppen até Strahler. Pernambuco: Revista Brasileira de Geografia Física, UFPE, 2010.

RAMOS, A. M.; SANTOS, L. A. R.; FORTES, L. T. G. Normais climatológicas do Brasil 1961 1990. Brasília: INMET, 2009. 465p.

ROCHA, T.; PERES, S. M., BÍSCARO, H. H.; MADEO, R.; BOSCARIOLI, C. Tutorial sobre Fuzzy-c-Means e Fuzzy Learning Vector Quantization: Abordagens Híbridas para Tarefas de Agrupamento e Classificação. Revista de Informática Teórica e Aplicada, v.19, n.1, 2012.

SECRETARIA DE ESTADO DE MEIO AMBIENTE E DESENVOLVIMENTO SUSTENTÁVEL. Zoneamento Ecológico-Econômico de Minas Gerais. Disponível em http://www.zee.mg.gov.br/. Acesso em 18 de novembro de 2014.

TUBELIS, A.; NASCIMENTO, F. J. L. Meteorologia descritiva: fundamentos e aplicações. São Paulo: Nobel, 1984. 374p. 